23

\title{
Square Porous Core Microstructure Fiber for Low Loss Terahertz Applications*
}

\author{
(C) Md.Ahasan Habib ${ }^{1}$ and Md.Shamim Anower ${ }^{2}$ \\ ${ }^{1}$ Bangabandhu Sheikh Mujibur Rahman Science \& Technology University, \\ 8100 Gopalganj, Bangladesh \\ ${ }^{2}$ Rajshahi University of Engineering and Technology, \\ 6204 Rajshahi, Bangladesh \\ e-mail: habib.eee.116.ah@gmail.com
}

Received November 20, 2018

Revised November 20, 2018

Accepted December 28, 2018

A new kind of square lattice porous core microstructure fiber is proposed for promising low loss terahertz applications. To analyze the guiding characteristics of proposed fiber Finite Element Method (FEM) based Comsol V4.2 software is used. The proposed fiber structure is very simple and easy to realize. The numerical results ensures that this proposed microstructure fiber exhibits low effective absorption loss of $0.06 \mathrm{~cm}^{-1}$, low confinement loss of $9.2 \cdot 10^{-3} \mathrm{~cm}^{-1}$, low bending loss of $8.8 \cdot 10^{-9} \mathrm{~dB} / \mathrm{m}$ and very high power fraction of $47 \%$ through the core at $1 \mathrm{THz}$ simultaneously. Moreover, our proposed fiber offers very low dispersion variation of $0.85 \pm 0.12 \mathrm{ps} / \mathrm{THz} / \mathrm{cm}$ over a wide range of frequency from 0.7 to $1.15 \mathrm{THz}$. The investigated results indicates that this fiber will be a good candidate in terahertz signal transmission as well as different terahertz devices.

DOI: $10.21883 /$ OS.2019.05.47671.335-18

* Полный текст статьи опубликован в английской версии журнала. 